\title{
Case Study: Primary Healthcare Clinical Placements during Nursing and Midwifery Education in Lesotho
}

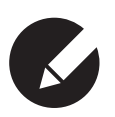

Alice Christensen, MSN, RN, CNS, Regional HIV and TB Advisor, Jhpiego, Dar es Salaam, Tanzania

Semakaleng Phafoli, PhD, RN, RM, PSE Technical Advisor, Jhpiego, Maseru, Lesotho Johannah Butler, RN, FNP, Baltimore, MD, USA

Isabel Nyangu, RN, RM, Scott School of Nursing, Christian Health Association of Lesotho, Lesotho

Laura Skolnik, MA, Associate Director, Maternal Child Survival Program, Washington, DC, USA

Stacie C. Stender, MSN, MSc Inf Dis, FNP, Senior Technical Advisor, HIV/TB/ID, Jhpiego, Cape Town, South Africa

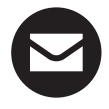

Correspondence may be directed to:

Alice Christensen

E-mail: alice.christensen@jhpiego.org 
Abstract

In Lesotho, primary healthcare is the main access point for health services. While nurses and midwives provide most of the care at this level, assessments of the clinical education programs have highlighted gaps in primary healthcare experiences for nursing and midwifery students. This case study examines placement of nursing and midwifery students in primary health clinics alongside preceptors. The placements provide students with varied clinical experience, better preparing them to practice in primary healthcare clinics. To date, more than 700 nursing and midwifery students have been placed in 40 rural health centres and 228 preceptors have been trained. The government is scaling up the program nationally.

\section{Introduction/Background}

The Kingdom of Lesotho is a small, landlocked, mountainous country in Southern Africa. The majority of the population of 1.8 million subsists on farming (World Bank 2015) and three-quarters live in rural areas (United Nations 2015). Despite its small size, the country faces extraordinary health challenges; nearly one-quarter of adults 15-49 years of age are living with HIV (22.9\%) (UNAIDS 2014) and Lesotho has the world's second highest tuberculosis incidence rate at 916 cases per 100,000 population (WHO 2014a; WHO 2014b). Lesotho also has one of the highest maternal mortality ratios in the world at 490 per 100,000 live births, with a lifetime risk of maternal death at 1 in 64 (WHO 2014c).

The country's health workforce is challenged to meet the needs of its population. The nursing and midwifery workforce is six per 10,000 compared to neighboring South Africa's 41 per 10,000 and 11 per 10,000 for the Africa region (WHO 2009). In Lesotho, over half (54\%) of nurse and midwife posts remain vacant in rural areas (Ntlale and Duma 2012).

Participation in primary healthcare rotations in rural areas during nursing and midwifery studies is an educational intervention noted by the World Health Organization
(WHO) for attracting, recruiting and retaining health workers in rural areas (WHO 2011). Research has demonstrated that clinical experiences acquired in rural communities can influence the locations in which students choose to practice after graduation, can aid students to develop professional networks in rural areas and can increase awareness about rural health (Bennet et al. 2014; Couper et al.2007). This case study describes the approach taken to increase nursing and midwifery students' exposure to primary healthcare skills in Lesotho.

\section{Intervention}

It is vital that nursing and midwifery students acquire the skills and competencies needed for rural deployment and also experience the realities of working in rural health centres in order to build their confidence to accept these posts as places of employment. Pre-service primary healthcare clinical experiences can serve as the link between community health theory and practice and are crucial for clinical skills development and professional socialization (Lofmark et al. 2008).

The United States Agency for International Development's (USAID's) Maternal Child Health Integrated Program (MCHIP), implemented through Jhpiego, began work in 
Lesotho in 2011 with a specific focus on strengthening pre-service nursing and midwifery education. To address the absence of a primary healthcare emphasis in preservice education, MCHIP supported clinical placements in primary care settings for certificate-level nursing assistant and diploma-level registered nursing and midwifery students. The placements were designed to place small cohorts of four to six students with trained preceptors to provide the students with clinical experiences that reflect the country's needs, improve oversight by preceptors and increase confidence in students' delivery of primary healthcare skills. Other activities were conducted in partnership with the Nursing Directorate in the Ministry of Health $(\mathrm{MOH})$ (see Table 1) that were congruent strategies recommended by WHO for rural workforce development in order to address equally compelling health workforce retention issues.

\section{Methodology/Change Process}

Lesotho has six schools of nursing education; five of which also provide midwifery education. Four of the schools are faithbased, overseen by the Christian Health Association of Lesotho; the remaining two are government-run schools. The National University of Lesotho, which offers the only degree program, has a five-year combined nursing and midwifery program of study. Five schools offer a nursing diploma after three years of study. Three schools offer a two-year certificate program for nursing assistants. Nursing assistants have a limited scope of nursing compared to their general nursing counterparts, similar to vocational nurses in many countries. Lesotho midwifery education is a one-year post-basic nursing diploma program that is offered in four of the five schools of nursing.

Table 1. WHO strategies to improve attraction, recruitment and retention of health workers in remote and rural areas compared to Lesotho's workforce development activities

\begin{tabular}{|l|l|}
\hline $\begin{array}{l}\text { World Health Organization recommended } \\
\text { interventions or strategies }\end{array}$ & Lesotho activities \\
\hline Increased enrollment of rural students & $\begin{array}{l}\text { A special retention package was developed for nurses at } 46 \text { hard-to-reach } \\
\text { health centres to encourage students in rural areas to seek nursing as a } \\
\text { career path. }\end{array}$ \\
\hline Rural clinical rotations & $\begin{array}{l}\text { The MOH partnered with MCHIP/Jhpiego to place nursing and } \\
\text { midwifery students in rural health clinics. }\end{array}$ \\
\hline Primary healthcare and rural health curriculum & $\begin{array}{l}\text { The MOH partnered with global initiatives (Millennium Challenge Corporation/ } \\
\text { Health Systems Strengthening Project and Nurse Education Partnership } \\
\text { Initiative) in a review of the primary healthcare components of both the } \\
\text { midwifery and general nursing curricula. }\end{array}$ \\
\hline Regulation of standards and scope of practice & $\begin{array}{l}\text { Lesotho Nursing Council, with support from MCHIP, reviewed and revised the } \\
\text { national nurse practice act. Scopes of practice, standards and competencies } \\
\text { are currently being revised. }\end{array}$ \\
\hline Financial incentives & $\begin{array}{l}\text { The MOH entered into negotiations with the Global Fund for money to increase } \\
\text { nurse and midwife salaries. }\end{array}$ \\
\hline Scholarships and bonuses & $\begin{array}{l}\text { The nongovernmental organization Irish Aid is offering signing bonuses, } \\
\text { televisions, telephones, housing and travel allowances to health workers } \\
\text { for working in rural areas. }\end{array}$ \\
\hline Personal and professional support & $\begin{array}{l}\text { The MOH partnered with MCHIP/Jhpiego and other partners to provide training } \\
\text { and supportive supervision/mentoring for preceptors in their clinical settings. }\end{array}$ \\
\hline Continuing education programs & $\begin{array}{l}\text { Lesotho Nursing Council's professional development program, which is linked to } \\
\text { re-licensure, was revised to include credit for preceptors overseeing students in } \\
\text { rural clinical placements. }\end{array}$ \\
\hline Improvement of clinic and rural infrastructure & $\begin{array}{l}\text { The MOH partnered with Millennium Challenge Corporation to build or revitalize } \\
\text { more than 80\% of Lesotho's health centres. }\end{array}$ \\
\hline
\end{tabular}


Initial pre-service education assessments of nursing and midwifery programs conducted in 2009/2010 highlighted gaps in student education and clinical experiences and indicated that most students were placed in hospital sites without trained preceptors and where the nursing staff had little time to serve as preceptors. Despite the fact that primary healthcare services are most in demand, in Lesotho, the nursing and midwifery programs did not include community and primary healthcare clinical experiences. Students' lack of experience was illustrated in their consistently low community health test scores.

To fill the need for nurses at primary health clinics, MCHIP conducted a pilot placement in 2012. The pilot was designed to 1) ensure graduates were competent and confident in primary healthcare skills upon graduation; 2) contribute to increasing recruitment and retention of nurses and midwives in rural areas; and 3) contribute to a workforce that was effective in addressing the health needs of the community and the nation.

Four faith-based nursing and midwifery schools agreed to place 15 students for two-tofour-week clinical rotations (based on the school's preference and study calendar) at three primary health clinics, the majority in rural areas, with students staying on-site and being supervised by clinical preceptors who were trained for that role by MCHIP personnel. Based on the feedback from the pilot, the placement project expanded in 2013.

During the 2012/2013 school year, 31 nurse educators and 62 clinical nursing staff were trained as preceptors. The five-day training for preceptors focused on development of clinical teaching skills, how to provide effective feedback to students and methods of documentation for the purpose of monitoring and evaluation. MCHIP provided on-site supportive supervision to all preceptors after training. Not all health centres that hosted students had trained preceptors during the first clinical placements due to time and financial constraints. MCHIP provided support to school-based nursing educators to meet with the preceptors and/or nurse-in-charge of the health centres before the placements and to visit students during their primary healthcare rotations.

Health centre assessments were conducted prior to student placement and guided MCHIP to ascertain what items were needed for the clinical rotations to be successful. Based on the assessments, the project supported development of primary healthcare clinical evaluation tools, provided transportation for students and nurse educators to and from clinical sites, secured accommodations and purchased necessary supplies for students during their clinical placements-for example, cook stoves, beds and solar lamps.

\section{Results}

Between January and June 2013, a total of 192 students from the four nursing education institutions were placed in 35 health centres for a single rotation lasting two to four weeks (Table 2). This case study reports the findings

Table 2. Students placed at health centres between January and June 2013, by school and cadre

\begin{tabular}{|l|l|l|l|l|l|}
\hline $\begin{array}{l}\text { Name of } \\
\text { school }\end{array}$ & $\begin{array}{l}\text { Nursing assistant } \\
\text { students } \\
n\end{array}$ & $\begin{array}{l}\mathbf{2}^{\text {nd }} \text { year general } \\
\text { nursing students } \\
n\end{array}$ & $\begin{array}{l}\mathbf{3}^{\text {rd }} \text { year general } \\
\text { nursing students } \\
n\end{array}$ & $\begin{array}{l}\text { Midwifery } \\
\text { students } \\
n\end{array}$ & $\begin{array}{l}\text { All students } \\
\text { N }\end{array}$ \\
\hline Maluti & N/A & N/A & 10 & 10 \\
\hline Paray & 18 & N/A & 28 & N/A & 46 \\
\hline Roma & N/A & 23 & 22 & 19 & 64 \\
\hline Scott & 22 & 21 & N/A & 29 & 72 \\
\hline All Schools & 40 & 44 & 50 & 58 & 192 \\
\hline
\end{tabular}


taken from the program's evaluations, which included 15 questions with a Likert-like scale survey and four open-ended questions: 1) state three clinical skills you feel have most improved during this clinical placement; 2) list three of the best experiences of this placement; 3) upon completion of your training, would you like to work in a similar rural clinic? Briefly explain your answer; and 4) list three areas that need improvement in regard to this clinical placement.

Each of the 192 students who had a clinical placement in a primary healthcare facility received the questionnaire; 161 students completed questionnaires (84\% response rate); a total of 197 questionnaires were completed because some students filled out multiple questionnaires as they rotated to different clinical sites during their placement. The evaluations sought to identify placement strengths and weaknesses, provide the students with a venue to comment on their clinic placements and provide recommendations to enhance the learning environment of the placements. Each of the four open-ended questions was reviewed and broad themes were developed for each question.

Figure 1. Responses to the statement "The placement enhanced my clinical skills"

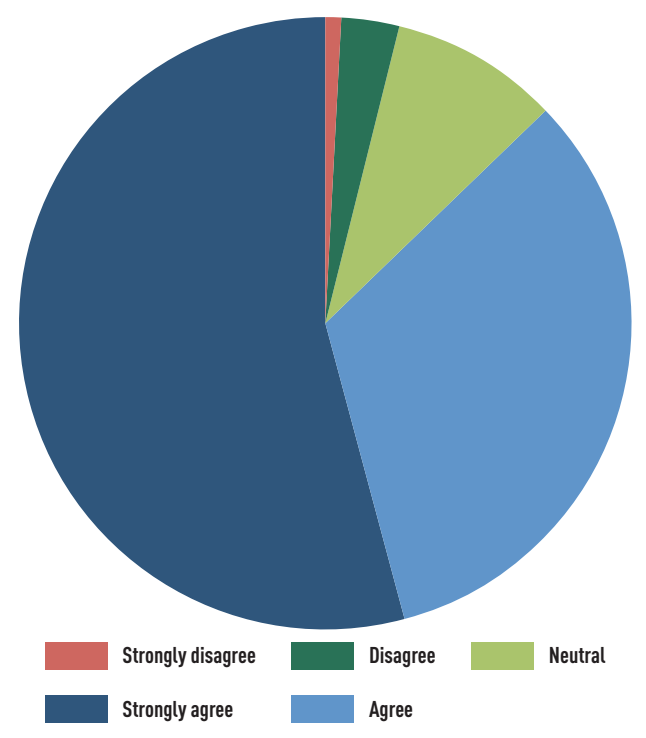

\section{Clinical Skills Improvement}

Overall, the majority of the questionnaire responses $(n=171)$ agreed or strongly agreed that the placement enhanced their clinical skills (Figure 1) and their confidence in working in a rural clinic improved as a result of the clinical placement (88\%).

A common theme identified by the students was that the placement provided a diverse clinical learning experience, including a wide variety of patient presentations and clinical skills practiced. A third year Roma nursing student stated there were many patients with different conditions that upgraded my skills/improved experience. Another theme noted that the primary healthcare clinics provided a good clinical learning atmosphere.

Six themes were identified from the students' answers when they were asked to identify skills they had most improved following their primary healthcare placement (Table 3). Thirty-two percent of questionnaires listed diagnosis and treatment skills as most improved; all cadres of students felt that their communication skills and maternal and child healthcare skills improved (12\% and $22 \%$ respectively). Other skills that were most improved included those specific to HIV care, such as testing, counseling and HIV care and treatment; performing physical examinations; and providing health education.

\section{Willingness for Deployment in Primary Health Clinics Following Graduation}

The majority of questionnaire responses $(68 \%)$ indicated that students would like to work in a similar setting after graduation (134 yes; 45 maybe; 18 no). Six themes were identified as reasons students were willing to work in rural clinics: independence, challenging and diverse clinical care, supportive staff and community, the need for staff and having had a good learning experience. For example, one student wrote on independence, I was able to do everything ... in a hospital, we expect the doctor to do everything. 
Table 3. Skills self-identified by students as most improved following primary healthcare clinical placement

\begin{tabular}{|l|l|l|l|}
\hline Rank & Theme & $\begin{array}{l}\text { Student responses to most improved skills } \\
\text { practiced during clinical rotation }\end{array}$ & $\begin{array}{l}\text { Number of questionnaire } \\
\text { responses* (\%) }\end{array}$ \\
\hline 1 & $\begin{array}{l}\text { Diagnosis and treatment of } \\
\text { primary health conditions }\end{array}$ & $\begin{array}{l}\text { - Identifying and treating diseases } \\
\text { - Consulting and diagnosing patients }\end{array}$ & 154 (32) \\
\hline 2 & Maternal and child health & $\begin{array}{l}\text { - Managing pediatric patients } \\
\text { - Assessing pregnant woman during antenatal care } \\
\text { - Caring for pregnant woman } \\
\text { - Offering family planning }\end{array}$ & $106(22)$ \\
\hline 3 & HIV Management & $\begin{array}{l}\text { - Counseling and testing for HIV } \\
\text { - Initiating of adults and children on ART }\end{array}$ & $79(17)$ \\
\hline 4 & Communication/ counseling & $\begin{array}{l}\text { - Counseling patients } \\
\text { - Communicating with diverse populations }\end{array}$ & $56(12)$ \\
\hline 5 & Physical examination & - Performing head-to-toe examinations & $24(5)$ \\
\hline 6 & Health education & - Providing health education & $23(5)$ \\
\hline
\end{tabular}

* The number of responses was greater than the total number of students because a student could provide multiple answers and students who rotated through multiple clinics filled out one survey per clinic rotation.

Students who answered "maybe," overwhelmingly stated that they would work in rural areas if issues of resources could be addressed, including transportation, electricity and water, and improvement of the infrastructure of the clinics.

Less than $10 \%(n=18)$ of the students participating in this program stated that they would be unwilling to work in a similar rural clinic following completion of their programs. Reasons included the poor clinic work environments, location in rural areas with limited resources and infrastructure, preference for hospital work, distance from family and already having a job following program completion.

\section{Suggestions for Improvement of Clinical Placements}

Overall, the areas students identified for improving clinical placements are also common reasons rural nurses give for leaving their jobs, including inadequate staffing and lack of electricity, water and supplies (Mokoka et al. 2010). Additionally, students thought that the experience could be improved by having greater oversight from faculty of their schools during the placement. Students from all cadres and schools stated that having a longer duration for the clinical placement would improve the experience. A second-year nursing student who underwent a two-week rotation, echoed many other students, the duration should be at least a month so that we shall be well equipped with clinical experience.

\section{Discussion/Conclusion}

Student nurses and student midwives need pre-service clinical experiences that are relevant to their deployment post-graduation and that are responsive to national health priorities. If the majority of nurses work in primary healthcare but only have clinical experiences at tertiary hospitals, then there is a mismatch of clinical education with skills required in the workplace. The evaluation of participants' experience during this clinical placement documented that students felt they improved their skills in diagnosis and treatment of primary health conditions, providing maternal and child health and HIV/AIDS care, which corresponds closely with national health needs. In addition, many of these students will be deployed upon graduation to health facilities with few or no doctors, which essentially requires these nurses to have diagnosis and treatment skills that were strengthened during their clinical placements. 
Placing students at clinics presents extensive challenges and requires close and ongoing collaboration between the $\mathrm{MOH}$, donors, clinical preceptors and nursing and midwifery faculty; for example, developing and maintaining a dialogue between the primary healthcare clinics and the schools. As a result of this study, we recommend that each school identify a focal person and that ongoing support be provided to schools to ensure clinics are visited and to coordinate planning, which will contribute to improved communication and coordination between facilities and schools. Retention of nurses and midwives remains a challenge for Lesotho; however, the national scale up of this program addresses key issues related to recruiting and retaining staff in rural areas by exposing students to the realities of healthcare priorities in Lesotho before deployment.

One major success of the program is that the $\mathrm{MOH}$ has budgeted for primary healthcare clinical placements for students as of 2015. MCHIP support covered the initial start-up costs of the placements; however, ongoing costs such as transport of students and nurse educators as well as additional training of preceptors will be covered by the Lesotho government, ensuring government ownership and sustainability of the program.

Due to its success, the placement project was expanded from the four original institutions to the additional two nursing schools in January 2015; all nursing schools in the country are now participating in the activity. To date, over 700 students have experienced primary healthcare clinical placements as part of their nursing and midwifery education, 42 health centres have hosted students and 228 preceptors have been trained and supported. Based on the evaluations and feedback from the 2012/2013 school year, MCHIP provided the schools with additional resources, such as text books and multimedia learning materials and learning models at select health centres.

The primary health clinic is often the first point of contact individuals and communities have with healthcare providers. If client healthcare needs are well managed at the primary care level, there will be fewer referrals to hospitals and a healthier population. Nursing and midwifery students perceive clinical practice settings as most influential in acquiring needed skills and expertise to provide primary healthcare services (Doherty and Govender 2004). Pre-service primary healthcare clinical rotations can be used effectively to demonstrate the realities of healthcare while at the same time enhancing students' knowledge and skills. Finally, if clinical placements in rural settings improve students' confidence, graduates may be more willing to accept rural posts, thereby filling many "hard to fill" positions that often remain vacant for years and reducing delays in the provision of care while ensuring patients care needs are met.

\section{Acknowledgements}

First and foremost the authors would like to thank the nursing and midwifery schools of Lesotho, the preceptors, faculty and students and the Christian Health Alliance of Lesotho, all who made the project a success. We would like to acknowledge the Directorate of Nursing Services who saw the value in these placements and has committed to their continuation, and the United States Agency for International Development who supported this program.

\section{Financial disclosure}

This work has been supported by the President's Emergency Plan for AIDS Relief (PEPFAR) through the U.S. Agency for International Development (USAID) under the terms of Cooperative Agreement No. GHS-A-00-08-00002-000. USAID staff did not play a role in data collection. The views expressed in this manuscript do not represent USAID or US Government opinions. The World Health Population Journal editors have sole editorial responsibility for the content of this manuscript. 


\section{References}

Bennett, P., D. Jones. J. Brown and V. Barlow. 2013. "Supporting Rural/Remote Primary Health Care Placement Experiences Increases Undergraduate Nurse Confidence." Nurse Education Today 33: 166-72.

Couper, I., J. Hugo, H. Conradie and K. Mfenyana. 2007. "Influences on the Choice of Health Professionals to Practice in Rural Areas." South African Medical Journal. 97: 1082-86.

Doherty, J. and R. Govender. 2004. "The Cost-Effectiveness of Primary Care Services in Developing Countries: A Review of the International Literature." Disease Control Priorities Project Working Paper No. 37. Washington DC, USA. Retrieved June 18, 2015. <http://whqlibdoc.who.int/publications/2011/9789241501262_eng.pdf?ua=1>.

Lofmark, A., G. Hansebo, M. Nilsson and L. Tornkvist. 2008. "Nursing Students' Views on Learning Opportunities in Primary Health Care." Nursing Standard. 23: 13 35-43.

Mokoka, E., M. Oosthuizen and V. Ehlers. 2010. "Retaining Professional Nurses in South Africa-Nurse Managers' Perspectives.” Health SA Gesondheid. 15(1):9. doi: 10.4102/hsag.v15i1.484.

Ntlale, M.E. and S.E. Duma. 2012. "The Costs and Benefits of Nurse Migration on Families: A Lesotho Experience". Curationis. 13: 1 doi: 10.4102/Curationis.34i1.13.

UNAIDS. 2014. Lesotho. Retrieved June 18, 2015. <http://www.unaids.org/en/regionscountries/countries/lesotho/>.
United Nations. 2015. "Lesotho Country Profile." Retrieved June 18, 2015. <http://data.un.org/ CountryProfile.aspx?crName=Lesotho $>$.

World Bank. 2015. "Lesotho Overview." http:// www.worldbank.org/en/country/lesotho/overview Retrieved June 182015.

World Health Organization (WHO). 2009. "Comprehensive Analytical Profile: Lesotho." Retrieved August 24, 2015. http://www.aho. afro.who.int/profiles_information/index.php/ Lesotho:Analytical_summary_-_Health_workforce World Health Organization (WHO). 2011. "Increasing Access to Health Workers in Remote and Rural Areas. Technical Report No 1. Retrieved June 18, 2015. <http://whqlibdoc.who.int/publications/2010/9789241564014_eng.pdf>.

World Health Organization (WHO). 2014a. "WHO Global Tuberculosis Report, 2014." Retrieved June 18, 2015. http://www.who.int/tb/ publications/global_report/en/.

World Health Organization (WHO). 2014b. Global Tuberculosis Report 2014 Key indicators for the WHO African Region. Retrieved June 18, 2015. http://www.who.int/tb/publications/ global_report/indicators_african_region.pdf?ua =1

World Health Organization (WHO). 2014c. "Trends in Maternal Mortality 1990 - 2013 Estimates by WHO, UNICEF, UNFPA, the World Bank and the United Nations Population Division". Geneva, World Health Organization. Retrieved September 12, 2015. <http://apps.who.int/iris/ bitstream/10665/112682/2/9789241507226_ eng.pdf?ua $=1>$.

\section{Better healthcare... everywhere.}

